\title{
Investigation of stearic acid additive effects on the mechanochemical synthesis of silver nanoparticles - CORRIGENDUM
}

\author{
Behruz Khakan, Abbas Shahroozi, Ahmad Afsari, and Seyed Reza Hosseini
}

doi: https://doi.org/10.1017/S0885715617000203, Published by Cambridge University Press, 28 February 2017.

In Khakan et al. (2017), Ahmed Asari was omitted from the list of authors. The correct list of authors is Behruz Khakan, Abbas Shahroozi, Ahmad Afsari, and Seyed Reza Hosseini. The online and print versions of the article have been corrected to reflect the correct authorship and affiliation with approval from all authors. Additionally, the affiliation for
Abbas Shahroozi has been corrected to the Department of Materials Science and Engineering at Shiraz University.

The authors apologize for these errors.

Khakan, B., Shahroozi, A., Afsari, A., and Hosseini, S. R. (2017). "Investigation of stearic acid additive effects on the mechanochemical synthesis of silver nanoparticles," Powder Diffraction. 32(2), 93-96. doi: 10.1017/ S0885715617000203. 